\title{
RESPOSTAS DE PLANTAS DE Schizolobium amazonicum [S. parahyba var. amazonicum] E Schizolobium parahyba [Schizolobium parahybum] À DEFICIÊNCIA HÍDRICA ${ }^{1}$
}

\author{
Cláudio José Reis de Carvalho²
}

\begin{abstract}
RESUMO - Plantas jovens de S. amazonicum (paricá) e S. parahyba (guapuruvu) foram submetidas a dois ciclos de deficiência hídrica em casa de vegetação. O déficit hídrico induziu o aumento dos teores de aminoácidos solúveis totais, prolina, açúcares solúveis totais e $\mathrm{K}^{+}$nos tecidos foliares, ocasionando o abaixamento do potencial osmótico em ambas as espécies. Porém, a análise dos resultados das curvas pressão-volume indica que as espécies respondem, de maneira diferente, ao estresse hídrico e o $S$. amazonicum apresenta maior capacidade de adaptação osmótica do que o $S$. parahyba.
\end{abstract}

Palavras-chave: Paricá, guapuruvu, estresse hídrico, osmorregulação, pressão-volume e potencial osmótico.

\section{RESPONSES OF Schizolobium amazonicum [S. parahyba var. Amazonicum] AND Schizolobium parahyba [Schizolobium parahybum] PLANTS TO WATER STRESS}

\begin{abstract}
Juvenile plants of S. amazonicum (paricá) and S. parahyba (guapuruvu) were subjected to two cycles of water stress in greenhouse conditions. The water deficit induced the increase in total soluble amino acids, proline, total soluble sugars and $K^{+}$contents in the leaf tissues, lowering osmotic potential values in both species. However, the analysis of the pressure-volume curve results suggests that the species respond differently to water stress, and that $\boldsymbol{S}$. amazonicum presents greater capacity of osmotic adaptation than S. parahyba.
\end{abstract}

Keywords: Paricá, guapuruvu, water stress, osmoregulation, pressure-volume and osmotic potential.

\section{INTRODUÇÃO}

A espécie de crescimento rápido Schizolobium amazonicum [S. parahyba var. amazonicum], conhecida como paricá, vem sendo amplamente utilizada na região amazônica em associações silvipastoris, agroflorestais ou, mesmo, em plantios homogêneos, visando à indústria de laminados (BRIENZA JÚNIOR et al., 1991).

Grande parte das plantações que utilizam essa espécie situam-se em regiões sujeitas à deficiência hídrica decorrente da má distribuição de chuvas, sendo comum a ocorrência de estações secas com aproximadamente seis meses de pluviosidade, em torno de $100 \mathrm{~mm}$ (JIPP et al., 1998). Apesar de somente existirem observações empíricas a esse respeito, pode-se constatar que nesses períodos as plantas recém-instaladas no campo passam por deficiência hídrica acentuada, causada por elevados níveis de radiação incidente e pelas características de suas folhas; por serem biparipenadas, seguramente apresentam menores valores de resistência da camadalimite, podendo ser submetidas, assim, à grande perda de água.

\footnotetext{
${ }^{1}$ Recebido em 07.11.2003 e aceito para publicação em 10.08.2005.

${ }^{2}$ Embrapa - Centro de Pesquisa Agroflorestal da Amazônia Oriental, Caixa Postal 48, 66095-100 Belém-PA. E-mail:<carvalho@cpatu.embrapa.br>.
} 
O Schizolobium parahyba [Schizolobium parahybum], conhecido como guapuruvu, típico da Mata Atlântica, tem sido apontado como alternativa mais tolerante à seca do que $S$. amazonicum, apesar de não existirem dados experimentais que demonstrem esse fato.

Essas duas espécies são muito semelhantes, entretanto, apesar de existirem vários trabalhos avaliando sua "performance" em aspectos, como crescimento, rendimento de madeira e sobrevivência em condições naturais (AMO et al., 1993; BRIENZA JUNIOR et al., 1991; POORTER, 1999; POORTER e HAYASHIDA OLIVER, 2000; SOUZA e VALIO, 1999), praticamente não existem dados na literatura comparando a resposta dessas duas espécies, quando submetidas à deficiência hídrica (LABOURIAU et al., 1961), em condições controladas.

Sabe-se que a deficiência hídrica provoca modificações na composição das células das plantas superiores, levando, em muitos casos, à produção de substâncias osmoticamente ativas. Esse processo, conhecido como osmorregulação, é um componente de grande importância no processo de tolerância à seca em várias espécies (BLUM et al., 1999; SUBBARAO et al., 2000; AYELE et al., 2001).

Procurou-se comparar as respostas de plantas jovens de Schizolobium amazonicum [S. parahyba var. amazonicum] e de Schizolobium parahyba [Schizolobium parahybum], quando submetidas à deficiência hídrica induzida por suspensão da irrigação, analisando-se as possíveis diferenças entre as duas espécies quanto à tolerância à seca.

\section{MATERIAL E MÉTODOS}

\section{Material vegetal e condições de cultivo}

Sementes de $S$. amazonicum, obtidas no Município de Açailândia, no Estado do Maranhão, e de $S$. parahyba, no Estado de São Paulo, foram escarificadas próximo à região do eixo embrionário, colocadas em bandejas forradas com papel absorvente úmido em câmara de germinação mantida a $30^{\circ} \mathrm{C}$ e $100 \%$ de umidade por 12 horas. As sementes entumecidas foram selecionadas e plantadas em sacos de plástico medindo $12 \mathrm{~cm}$ x $22 \mathrm{~cm}$, preenchidos com uma mistura de terriço (solo superficial de mata) e areia com a proporção volumétrica de 3:1.
As plantas foram cultivadas sob um telado de "Sombrite" com 50\% de interceptação da radiação solar incidente por 60 dias, sendo molhadas diariamente. Após esse período, foram selecionadas em função da uniformidade, plantadas em vasos de plástico perfurados de 20 L de capacidade, preenchidos com uma mistura de terriço, areia e esterco curtido $(3: 1: 0,5)$, cultivadas em casa de vegetação aberta lateralmente sob as mesmas condições de temperatura e umidade do ar externo, mas com radiação fotossinteticamente ativa (RFA) máxima de $1.200 \mathrm{mmol} \cdot \mathrm{m}^{-2} \cdot \mathrm{s}^{-1}$ (40\% de interceptação da radiação fotossinteticamente ativa máxima incidente de \pm 2.000 mmol. $\left.\mathrm{m}^{-2} \cdot \mathrm{s}^{-1}\right)$.

No ato do plantio, cada vaso recebeu $10 \mathrm{~g}$ de adubo NPK (formulação 10:28:20). As plantas foram irrigadas diariamente e, a cada semana, cada vaso recebeu $100 \mathrm{~mL}$ de uma solução $\left(2 \mathrm{~g} \mathrm{~L}^{-1}\right)$ de adubo comercial solúvel (20\% $\mathrm{N}$ total, $10 \%$ de $\mathrm{P}_{2} \mathrm{O}_{5}, 10 \%$ de $\mathrm{K}_{2} \mathrm{O}, 0,06 \%$ de $\mathrm{Mg}$, $0,14 \%$ de $\mathrm{B}, 1,5 \%$ de Zn e $0,08 \%$ de $\mathrm{Mn}$ ). As plantas foram cultivadas nessas condições durante 30 dias, até o início do experimento, quando contavam com três meses de idade.

\section{Imposição dos tratamentos}

As plantas foram separadas em dois grupos com 16 indivíduos de cada espécie, os quais foram posteriormente alocados em dois subgrupos de oito indivíduos. De cada um desses subgrupos, quatro plantas foram mantidas sob irrigação normal e quatro, submetidas ao secamento por suspensão da irrigação durante seis dias, perfazendo um primeiro ciclo de secamento. Ao final desse primeiro ciclo, os dois subgrupos foram reidratados durante três dias. Um subgrupo de cada espécie foi retirado e usado para diversas avaliações destrutivas, que constaram de curvas pressão-volume e coleta de discos de folhas para avaliações bioquímicas. O segundo subgrupo foi, então, submetido a um novo ciclo de secamento imposto de modo similar ao anterior, porém com duração de nove dias, seguidos de outros três de reidratação. As folhas de ambas as espécies são bi-paripenadas e, portanto, algumas observações foram efetuadas nos folíolos e outras, nos foliolulos.

\section{Características avaliadas}

No início de cada ciclo de secamento (dia zero) e a cada dois dias, foram avaliadas as características nas plantas do ciclo pertinente, segundo as metodologias descritas nas páginas seguintes: 
Potencial de base (pre-dawn) - foi medido com uma câmara de pressão, modelo EL540-300 (Wagtech International Ltd., Berkshire, England), no pecíolo de um folíolo da parte mediana da folha. Na véspera, as plantas a serem avaliadas foram cobertas com uma armação de madeira coberta com plástico negro $(0,8$ $\mathrm{m} \times 0,8 \mathrm{~m} \times 1,6 \mathrm{~m})$, a partir das 18 horas. As mensurações foram feitas no período das sete horas às oito horas do dia seguinte, ficando as plantas cobertas até o momento das mensurações. A cobertura de plástico foi retirada de cada planta individualmente no momento da medida e o folíolo, cortado e imediatamente inserido na câmara de pressão (o tempo decorrido entre a retirada da cobertura e a mensuração foi de \pm dois minutos).

Teor relativo de água no potencial de base - Após a medida do potencial de base, foram retirados 10 discos de $1 \mathrm{~cm}$ de diâmetro (um de cada foliolulo e cinco de cada lado do folíolo), os quais foram colocados em um tubo tipo Eppendorf de $5 \mathrm{~mL}$, fechados e pesados para obter a massa fresca. Esses mesmos discos foram colocados para flutuar em água destilada, contida em uma placa de Petri por 12 horas a $5{ }^{\circ} \mathrm{C}$, após o que foram enxugados superficialmente, colocados de novo no tubo Eppendorf e pesados para obter a massa saturada. Finalmente, os tubos foram abertos e colocados em estufa a $75^{\circ} \mathrm{C}$, por 72 horas, e novamente pesados para se obter a massa seca. O teor relativo de água foi calculado segundo Weatherley (1950).

Curvas pressão - volume - Os folíolos usados nas curvas pressão-volume foram coletados ao amanhecer do terceiro dia de reidratação das plantas. As bases foram colocadas em um vasilhame com água e o conjunto, envolto com saco de plástico para compor uma câmara úmida, onde os folíolos permaneceram por três horas para atingir a saturação máxima (PARKER e PALLARDY, 1987). Foi usada uma câmara de pressão semelhante à descrita anteriormente. Os folíolos foram expostos ao ar, em intervalos de tempo gradativamente maiores, para permitir a perda de água natural dos tecidos (TURNER, 1981), após o que foram avaliados o peso fresco e a nova pressão de equilíbrio. O procedimento foi terminado ao serem obtidos no mínimo 16 pares de pontos, quando os folíolos foram colocados para secar em estufa com ventilação forçada a $80{ }^{\circ} \mathrm{C}$, para ser obtido o peso de matéria seca. O peso na saturação foi obtido por extrapolação a um potencial zero da relação entre o peso de matéria fresca e o potencial de pressão dos quatro ou cinco primeiros pontos (LADIGES, 1975).
Análises bioquímicas - Paralelamente à coleta dos folíolos a serem usados nas curvas pressão-volume, foram retiradas duas amostras de 10 discos de $1 \mathrm{~cm}$ de diâmetro (um de cada foliolulo e cinco de cada lado do folíolo), os quais foram colocados em sacos de plástico, mergulhados em nitrogênio líquido e mantidos congelados até a sua utilização. O restante do tecido dos folíolos (somente o limbo) foi lavado em água destilada e secado a $80^{\circ} \mathrm{C}$ por 24 horas, sendo destinado à análise do teor de potássio, por fotometria de chama, em extratos aquosos, obtidos após a digestão em $\mathrm{H}_{2} \mathrm{SO}_{4}$ concentrado e $\mathrm{H}_{2} \mathrm{O}_{2}$ a $280{ }^{\circ} \mathrm{C}$.

Os teores de prolina foram avaliados segundo a metodologia descrita em Bates et al. (1973), e os aminoácidos e açúcares solúveis totais foram avaliados, espectrofotometricamente, após a extração com etanol $(70 \% \mathrm{v} / \mathrm{v})$ e a quente e purificação (desproteinização) dos extratos com um sistema de hidróxido de bário e sulfato de zinco. Os açúcares solúveis totais foram dosados pela reação com Antrona em ácido sulfúrico, usando-se curva de calibração com glicose (YEMM e WILLIS, 1954). Os aminoácidos solúveis totais foram dosados no mesmo extrato por reação com ninhidrina (YEMM e COCKING, 1954), usando-se na curva-padrão uma mistura de glicina, prolina e leucina.

\section{Tratamento estatístico}

O delineamento experimental foi o de blocos casualizados, arranjado em um esquema fatorial constando de duas espécies, dois tratamentos (seco e irrigado) e dois ciclos de secamento. Os resultados foram analisados usando o programa Systat versão 7.01. A significância das médias das diversas variáveis de resposta foram avaliadas, usando-se o teste de Bonferroni a 5\% de probabilidade.

\section{RESULTADOS E DISCUSSÃO}

A irrigação das plantas-testemunha foi suficiente para manter a boa hidratação, como pode ser visto na Figura $1 \mathrm{~A}$, pois os valores do potencial hídrico ao amanhecer se mantiveram entre -0,2 e -0,3 MPa. Nas plantas de ambas as espécies, a primeira suspensão da irrigação causou redução abrupta e quase linear dos valores do potencial hídrico ao amanhecer (Figura 1B), os quais passaram de valores semelhantes aos das plantas-testemunha (-0,2 e -0,3 MPa) para valores entre -1,5 e -2,0 MPa. Após a reidratação, durante o segundo ciclo de deficiência hídrica o abaixamento do potencial hídrico ao amanhecer deu-se de forma mais gradual do que no primeiro ciclo.

R. Árvore, Viçosa-MG, v.29, n.6, p.907-914, 2005 

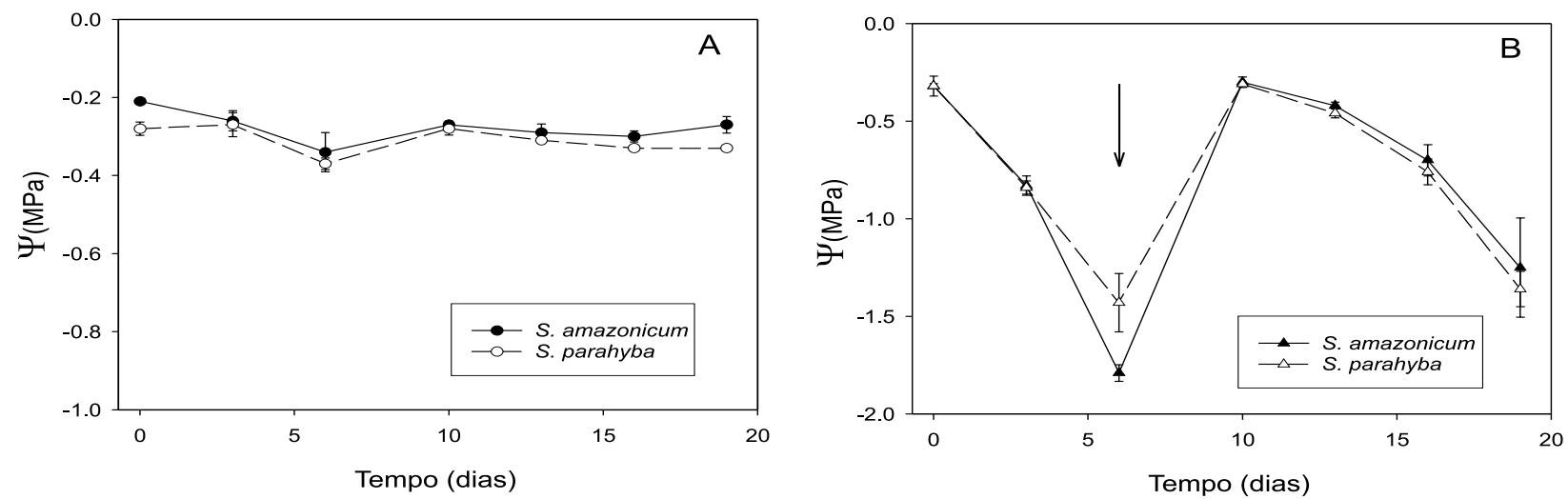

Figura 1 - Evolução do potencial hídrico de base ( $\psi$, Mpa. Observar a diferença de escalas) nas plantas irrigadas (A) e submetidas a dois ciclos de deficiência hídrica (B), interrompidos por um período de reidratação indicado pela flecha. As barras verticais representam o erro-padrão da média $(\mathrm{n}=4)$.

Figure 1 - Predawn leaf water potential ( $\psi, M p$ a) of control $(A)$ and water stressed plants $(B)$ for two consecutive cycles of water deficit. The arrow indicates the re-hydration day. Vertical bars stand for the mean standard error $(n=4)$. Note that the scales for leaf water potential are different.

Conceitualmente, o potencial hídrico ao amanhecer expressa um valor de equilíbrio entre o potencial hídrico do solo e o da planta (NILSEN e ORCUTT, 1996). Desde que o conteúdo de umidade de todos os vasos foi devidamente elevado até a saturação, tanto no período de três dias antes do início do primeiro ciclo quanto naquele que antecedeu o segundo e em que não foi observada queda de folíolos durante ou após o primeiro ciclo de secamento e reidratação, a mudança na evolução do potencial hídrico observada no segundo ciclo de seca pode ter sido devida às mudanças na economia

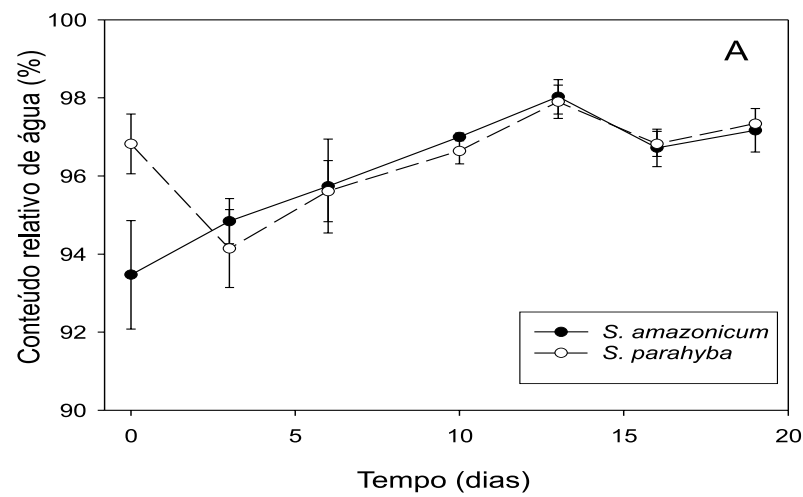

hídrica das plantas, com possíveis reduções nas taxas transpiratórias.

A evolução do conteúdo relativo de água dos tecidos foliares (Figura $2 \mathrm{AB}$ ) seguiu basicamente a mesma tendência observada nos valores do potencial hídrico com queda acentuada no primeiro ciclo de secamento. Observa-se que entre o primeiro e o sexto dia houve redução de valores entre 95 e $98 \%$ para aproximadamente $70 \%$. Novamente, durante o segundo ciclo de secamento a redução deu-se em taxas menores do que aquelas observadas no primeiro ciclo.

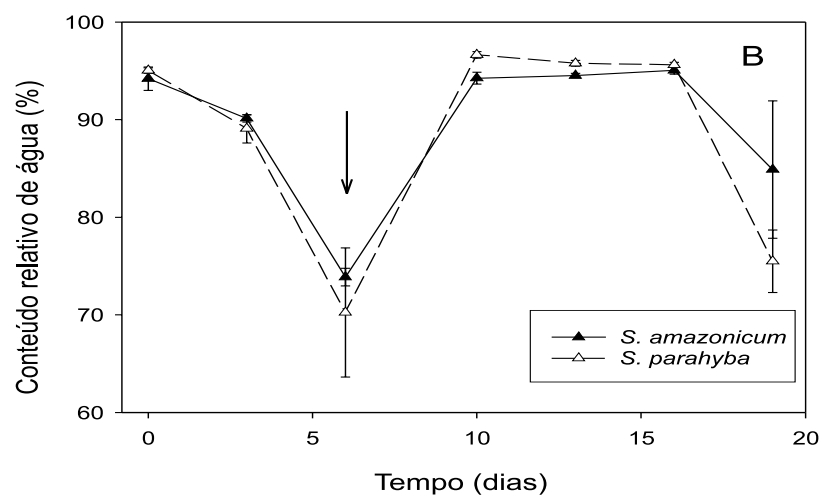

Figura 2 - Variação do conteúdo relativo de água dos tecidos foliares ( em \%. Observar a diferença de escalas) nas plantas irrigadas (A) e submetidas a dois ciclos de deficiência hídrica (B), interrompidos por um período de reidratação indicado pela flecha. As barras verticais representam o erro-padrão da média $(\mathrm{n}=4)$.

Figure 2 - Predawn relative water content of leaf tissue (\%), control (A) and water stressed plants (B), for two consecutive cycles of water deficit. The arrow indicates the re-hydration day. Vertical bars stand for the mean standard error $(n=4)$. Note that the scales for the leaf water potential are different.

R. Árvore, Viçosa-MG, v.29, n.6, p.907-914, 2005 
Os valores de potencial hídrico e teor relativo de água induzidos são semelhante àqueles observados no campo, em árvores mesófitas (NEPSTAD et al., 1994). Sob condições naturais, o desenvolvimento da deficiência hídrica geralmente dá-se de maneira gradual, enquanto em ensaios de plantas em vasos a imposição do déficit geralmente é muito rápida em razão do espaço radicular restrito. Em razão disso, alguns mecanismos adaptativos, como o acúmulo de substâncias osmoticamente ativas nas células e posterior abaixamento do potencial osmótico, ou não ocorrem ou se manifestam com menor intensidade (JONES e RAWSON, 1979).

No presente caso, o uso de vasos grandes (20 L) e dois ciclos de secamento permitiu a modificação das respostas do potencial hídrico e do teor relativo de água das folhas entre o primeiro e o segundo ciclo e, conseqüentemente, pode-se supor que o tratamento foi suficiente para provocar a ocorrência de mecanismos de adaptação.

Na Tabela 1, verificam-se os resultados das análises feitas nos tecidos de limbo foliar após a reidratação, ao final de cada ciclo de secamento. Pode-se constatar que houve aumentos significativos nos teores das principais substâncias osmoticamente ativas analisadas. Deve ser ressaltado que o acúmulo não se deveu a efeitos de concentração passiva, uma vez que as plantas, das quais os discos de folíolo foram coletados, tinham sido reidratadas e que medidas do potencial hídrico de base indicaram que a saturação fora atingida, assim como os resultados dos aminoácidos, açúcares e prolina foram expressos com base em área de folha e não em peso, para eliminar possíveis tendências geradas por diferenças na área foliar específica.

A deficiência hídrica provocou acúmulo de aminoácidos livres em ambas as espécies. A análise dos resultados indicou que houve diferença significativa entre tratamentos $(\mathrm{p}<0,001)$ e que ambas as espécies foram afetadas de maneira semelhante $(\mathrm{p}=0,709) \mathrm{em}$ ambos os ciclos. De modo geral, essa mesma tendência foi observada com relação ao acúmulo de prolina.

O grupo de substâncias que teve aumento mais expressivo foi o dos açúcares solúveis totais, no qual foram detectadas diferenças significativas nas interações entre espécies $\mathrm{x}$ tratamentos $\mathrm{x}$ ciclos $(\mathrm{p}=0,043)$. $\mathrm{O}$ segundo ciclo de secamento induziu o acúmulo de aproximadamente $13 \mathrm{mg} . \mathrm{cm}^{-2}$ nos tecidos de $S$. amazonicum.

O acúmulo dos aminoácidos e açúcares livres pode ser decorrente da restrição à síntese de proteínas e da hidrólise das reservas de amido, bem como de distúrbios causados pela deficiência de água nos tecidos do floema, reduzindo a sua translocação para outros órgãos (SUBBARAO et al., 2000). Esses compostos, além de proporcionarem vantagens, do ponto de vista do abaixamento do potencial osmótico e da manutenção da turgescência, servem de reservas de carbono e nitrogênio para a imediata retomada do crescimento, uma vez que as tensões ambientais sejam aliviadas (NILSEN e ORCUTT, 1996; SZEGLETES et al., 2000).

Tabela 1 - Modificação dos teores (em $\mu \mathrm{g}$ ou mg.cm ${ }^{-2}$ de área ou mg.kg-1 de massa seca) dos compostos osmoticamente ativos nos tecidos de folhas das plantas jovens de $S$. amazonicum e $S$. parahyba submetidas a dois ciclos de secamento ${ }^{(*)}$

Table 1 - Osmotically active compounds ( $\mu \mathrm{g}$ or $\mathrm{mg}_{\mathrm{cm}} \mathrm{cm}^{-2}$ of surface or $\mathrm{mg} \mathrm{kg}^{-1}$ dry weight) in leaf tissue of young plants of $S$. amazonicum and $S$. Parahyba subjected to two water deficit cycles(*).

\begin{tabular}{|c|c|c|c|c|}
\hline \multirow[t]{2}{*}{ Tratamento } & \multicolumn{2}{|c|}{ S. amazonicum } & \multicolumn{2}{|c|}{ S. parahyba } \\
\hline & $1^{\circ}$ ciclo & $2^{\circ}$ ciclo & $1^{\circ}$ ciclo & $2^{\circ}$ ciclo \\
\hline & \multicolumn{4}{|c|}{ Aminoácidos solúveis totais $\left(\mathrm{mg} . \mathrm{cm}^{-2}\right)$} \\
\hline Não-irrigado & $12,53( \pm 3,59)$ & $17,45( \pm 5,26)$ & $10,54( \pm 0,77)$ & $14,28( \pm 2,15)$ \\
\hline \multirow[t]{2}{*}{ Irrigado } & $5,74( \pm 0,45)$ & $6,39( \pm 0,22)$ & $8,42( \pm 1,15)$ & $6,33( \pm 0,77)$ \\
\hline & \multicolumn{4}{|c|}{ Prolina livre $\left(\mathrm{g} . \mathrm{cm}^{-2}\right)$} \\
\hline Não-irrigado & $1,50( \pm 0,39)$ & $1,90( \pm 0,14)$ & $1,42( \pm 0,28)$ & $1,55( \pm 0,19)$ \\
\hline \multirow[t]{2}{*}{ Irrigado } & $1,23( \pm 0,12)$ & $1,19( \pm 0,03)$ & $1,01( \pm 0,04)$ & $1,18( \pm 0,11)$ \\
\hline & \multicolumn{4}{|c|}{ Açúcares solúveis totais $\left(\mathrm{mg} . \mathrm{cm}^{-2}\right)$} \\
\hline Não-irrigado & $11,51( \pm 1,74)$ & $25,25( \pm 1,34)$ & $14,56( \pm 1,44)$ & $18,28( \pm 0,67)$ \\
\hline \multirow[t]{2}{*}{ Irrigado } & $10,34( \pm 0,60)$ & $11,96( \pm 0,83)$ & $14,03( \pm 1,80)$ & $13,24( \pm 1,21)$ \\
\hline & \multicolumn{4}{|c|}{ Potássio $\left(\mathrm{mg} \cdot \mathrm{kg}^{-1}\right)$} \\
\hline Não-irrigado & $23,92( \pm 1,06)$ & $20,56( \pm 0,78)$ & $22,65( \pm 0,63)$ & $24,30( \pm 0,93)$ \\
\hline Irrigado & $20,11( \pm 0,74)$ & $15,23( \pm 0,43)$ & $17,70( \pm 0,49)$ & $16,75( \pm 0,32)$ \\
\hline
\end{tabular}

(*) Cada resultado representa a média de quatro repetições, e os valores entre parênteses significam o desvio-padrão da média. 
O elemento osmoticamente ativo que mais respondeu aos ciclos de déficit foi o $\mathrm{K}^{+}$, que, embora não tenha apresentado diferenças significativas entre as duas espécies $(\mathrm{p}=0,446)$, mostrou diferenças significativas na interação espécies $\mathrm{x}$ ciclos $(\mathrm{p}<0,001)$. Portanto, podem ser sugeridas futuras investigações que avaliem os efeitos da nutrição com $\mathrm{K}^{+}$na tolerância ao déficit hídrico dessas espécies.

Os resultados obtidos com as curvas pressãovolume (Tabela 1) indicaram que, mesmo após três dias de reidratação, a deficiência de água induziu reduções significativas $(\mathrm{p}<0,001)$ no potencial osmótico na saturação $\left(\pi_{100}\right)$. Porém, as duas espécies reagiram diferentemente $(\mathrm{p}<0,001)$ aos dois ciclos de secamento. O potencial osmótico foi mais baixo mesmo nas plantas irrigadas de $S$. amazonicum, tanto no primeiro quanto no segundo ciclos. Portanto, essa espécie já apresenta diferenças no potencial osmótico em relação ao $S$. parahyba, mesmo em condições ideais de hidratação.

Os resultados do potencial osmótico no ponto de turgescência zero $\left(\pi_{\text {zero }}\right)$ seguiram a mesma tendência apresentada pelo potencial osmótico em plena saturação $\left(\pi_{100}\right)$, tendo sido detectado interação significativa entre as espécies e os tratamentos $(\mathrm{p}=0,029)$ (Tabela 2).

O valor do conteúdo relativo de água (CRA) no ponto de turgescência zero também variou entre as espécies e, embora não tenham sido encontradas diferenças significativas, os tecidos foliares de $S$. amazonicum suportaram as maiores reduções do conteúdo relativo de água $(87,6 \%)$, para que a turgescência das células fosse anulada.

A manutenção da turgescência em condições de déficit hídrico pode permitir o funcionamento adequado das rotas metabólicas, abertura mínima dos estômatos, para permitir fotossíntese, além de outros mecanismos, como o crescimento e expansão do caule e das raízes. Essa característica foi aparentemente influenciada pela sucessão dos ciclos de secamento, de maneira diferente nas espécies estudadas.

A relação entre o potencial de turgescência $(P)$ e o potencial hídrico $(\psi)$, derivados das curvas pressãovolume, é muito usada para avaliar os possíveis efeitos daosmorregulação(RITCHIEeHINCKLEY, 1975; TURNER, 1981, 1997). Na Figura 3, verifica-se que o decréscimo de $\mathrm{P}$, com a queda do potencial hídrico, ocorreu de maneira muito semelhante e consistente nos dois ciclos, nas plantas irrigadas de ambas as espécies, contudo os dois ciclos sucessivos de déficit modificaram a relação entre essas duas variáveis nos tecidos de $S$. amazonicum, não provocando mudanças nos tecidos de S. parahyba.

Em ambas as espécies, o volume relativo de água do simplasto não variou de forma significativa por efeito da aplicação dos dois ciclos de secamento. Assim, podese afirmar que as modificações da relação entre $\mathrm{P}$ e $\psi$, nos tecidos foliares de $S$. amazonicum, decorrem de ajustamento osmótico verdadeiro, decorrente do acúmulo de substâncias osmoticamente ativas (NILSEN e ORCUTT, 1996).

Tabela 2 - Valores do potencial osmótico no ponto de saturação $\left(\pi_{100}\right.$, Mpa), potencial osmótico no ponto de turgescência zero $\left(\pi_{\text {zero }}, \mathrm{Mpa}\right)$ e conteúdo relativo de água (CRA) no ponto de turgescência zero dos tecidos de folíolos de plantas jovens de $S$. amazonicum e $S$. parahyba submetidas a dois ciclos de secamento, estimados pela técnica de curvas pressão-volume ${ }^{(*)}$

Table 2 - Osmotic potential at saturation $\left(\pi_{100}\right.$, Mpa), osmotic potential at zero turgor $\left(\pi_{z e r o}\right.$, Mpa), and relative water content at zero turgor (CRA) for leaf tissues of juvenile plants of S. amazonicum and S. parahyba subjected to two cycles of water deficit

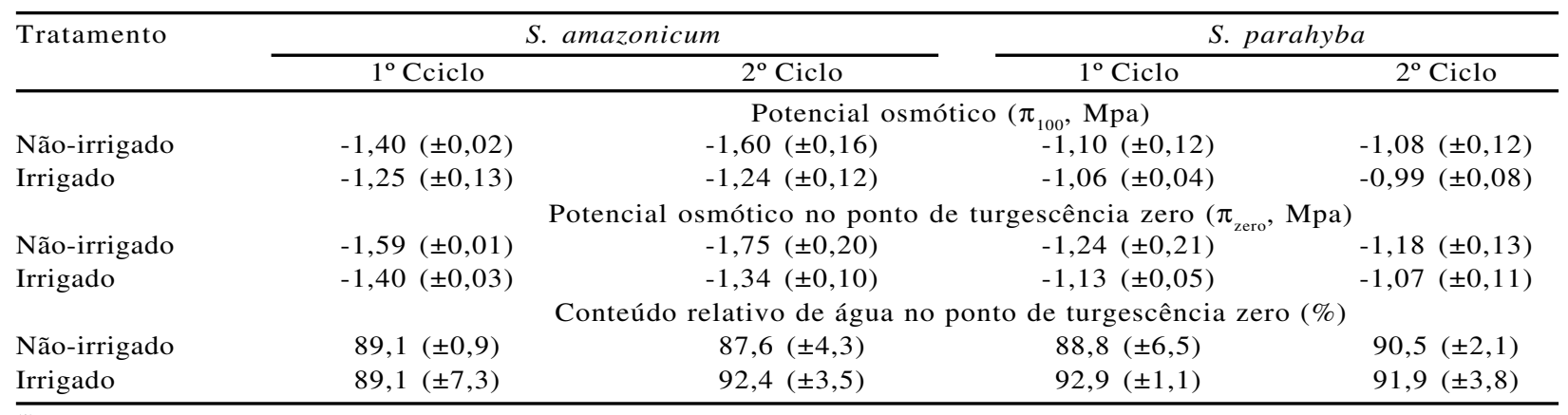

(*) Cada resultado representa a média de quatro repetições, e os valores entre parênteses indicam o desvio-padrão da média.

R. Árvore, Viçosa-MG, v.29, n.6, p.907-914, 2005 
Finalmente, pode-se dizer que o déficit hídrico induziu o surgimento do mecanismo de osmorregulação na espécie $S$. amazonicum. Em se tratando de espécie perene, esse fato é de grande importância como mecanismo de tolerância a períodos de deficiência hídrica que freqüentemente ocorrem no campo, pois, além da sobrevivência, a maior capacidade de adaptação dessa espécie favorece o crescimento e formação de biomassa nas épocas secas.
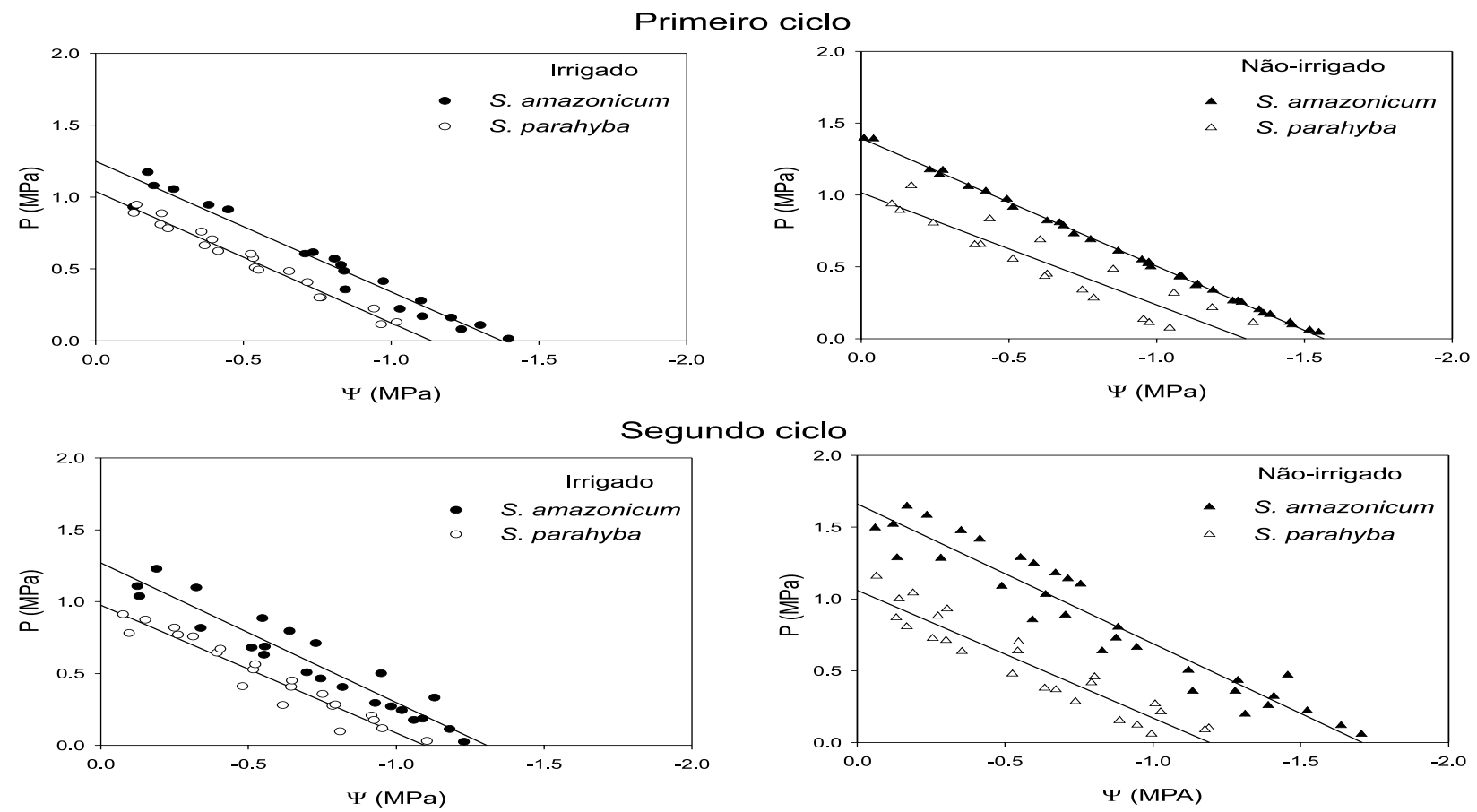

Figura 3 - Relação entre o potencial de pressão (P, MPa) e o potencial hídrico ( $\psi$, MPa) derivados a partir de curvas pressãovolume estabelecidas com folíolos das plantas irrigadas e submetidas a dois ciclos de deficiência hídrica, interrompidos por um período de reidratação. As retas representam a regressão linear entre as variáveis estabelecidas pelo método dos mínimos quadrados.

Figure 3 - Ratio between pressure potential ( $P, M P a)$ and water potential ( $\psi, M P a)$ calculated from pressure-volume curves for leaflets of irrigated plants and subjected to two water deficit cycles intercalated with one rehydration event. Lines represent the linear regression between variables determined by the least square method.

\section{REFERÊNCIAS BIBLIOGRÁFICAS}

AMO, R. S.; RAMOS, P. J.; DEL AMO, R. S. Use and management of secondary vegetation in a humid-tropical area. Agroforestry Systems, v. 21, p.27-42, 1993.

ARNON, D.I. Copper enzymes in isolated chloroplasts. Polyphenol oxidases in Beta vulgaris. Plant Physiology, v.24, p.1-14, 1949.

AYELE, M.; BLUM, A.; NGUYEN, HT. Diversity for osmotic adjustement and root depth in teff [Eragrostis tef (Zucc) Trotter]. Euphytica, v.121, n.3, p.237-249, 2001.
BATES, L.S.; WALDREN, R.P.; TEARE, I.D. Rapid determination of free proline for water-stress studies. Plant and Soil, v.39, p. 205-207, 1973.

BRIENZA JUNIOR, S.; YARED, J. A. G.; JARVIS, P. G. Agroforestry systems as an ecological approach in the Brazilian Amazon development. Agroforestry Systems, v.45, p.319-323, 1991.

BLUM, A.; ZHANG, JX; NGUYEN, HT. Consistent differences among wheat cultivars in osmotic adjustment and their relationship to plant production. Field Crops Research, v.64, n.3, p.287-291, 1999.

R. Árvore, Viçosa-MG, v.29, n.6, p.907-914, 2005 
JIPP, P. H.; NEPSTAD, D. C. Deep soil moisture storage and transpiration in forests and pastures of seasonally-dry Amazonia, Climatic Change, v.39, p.395-412, 1998.

JONES, M.M.; RAWSON, H.M. Influence of rate of development of leaf water deficits upon photosynthesis, leaf conductance, water use efficiency, and osmotic potential in sorghum.

Physiologia Plantarum, v.45, p.103-111, 1979.

LABOURIAU, L. G.; OLIVEIRA, J. G.;

LABOURIAU, M. L. S. Transpiração de

Schizolobium parahyba (Vell.) Toledo. I-

Comportamento na estação chuvosa, nas condições de Caeté, Minas Gerais, Brasil. Anais da Academia Brasileira de Ciências, v.33, n.2, p.237-258, 1961.

LADIGES P.Y. Somme aspects of tissue water relations in three populations of Eucalyptus viminalis Labill. New Phytologist, v.75, p.53-62, 1975.

MACKINNEY, G. Absorption of light by chlorophyll solutions. Journal of Biological Chemistry, v.144, p.315-323, 1941.

NEPSTAD, D.C. et al. The role of deep roots in the hydrological cycles of Amazonian forests and pastures. Nature, v. 372, n. 15, p. 666-669, 1994.

NILSEN, E.T.; ORCUTT, D.M. Physiology of plants under stress: abiotic factors. New York: John Wiley \& Sons, 1996. p.689.

PARKER W.C.; PALLARDY S.G. The influence of resaturation method and tissue type on pressurevolume analysis of Quercus alba L. seedlings.

Journal of Experimental Botany, v.38 n.188, p.535-549, 1987.

POORTER, L. Growth responses of 15 rainforest tree species to a light gradient: the relative importance of morphological and physiological traits. Functional Ecology, v.13, p.396-410, 1999.

R. Árvore, Viçosa-MG, v.29, n.6, p.897-905, 2005
POORTER, L.; HAYASHIDA OLIVER, Y. Effects of seasonal drought on gap and understorey seedlings in a Bolivian moist forest. Journal of Tropical Ecology, v.16, p.481-498, 2000.

RITCHIE, G.A.; HINCKLEY, T.M. The pressure chamber as a instrument for ecological research. Advances in Ecological Research, v.9, p.165-254, 1975.

SOUZA, R.P.; VALIO, I.F.M. Carbon translocation as affected by shade in saplings of shade tolerant and intolerant species. Biologia Plantarum, v.42, p.631-636, 1999.

SUBBARAO, G.V. et al. Osmotic adjustment, water relations and carbohydrate remobilization in pigeonpea under water stress. Journal of Plant Physiology, v.157, n.6, p.651-659, 2000.

SZEGLETES, Z. et al. Accumulation of osmoprotectants in wheat cultivars of different drought tolerance. Cereal Research Communications, v.28, n.4, p.403-410, 2000.

TURNER, N.C. Techniques and experimental approaches for the measurement of plant water status. Plant and Soil, v.58, p.339-366, 1981.

TURNER, N.C. Further progress in crop water relations. Advances in Agronomy, v.58, p.293-338, 1997.

WEATHERLEY, P.E. Studies in the water relations of the cotton plant. I- The field measurements of water deficits in leaves. New Phytologist, v.49, p.81-97, 1950.

YEMM, E. W.; COCKING, A. C. The determination of amino-acids winth ninhydrin. Analyst, v. 80, p. 209-214, 1955.

YEMM, E. W.; WILLIS, A. J. The estimation of carbohydrates in plants extracts by antrone. Biochemical Journal, v. 57, p.508-514, 1954.

\footnotetext{
R. Árvore, Viçosa-MG, v.29, n.6, p.897-905, 2005
} 